\title{
The Burden of Hypertension and Diabetes Mellitus in Rural Communities in Southern Nigeria by Alphonsus Rukevwe Isara and Patrick Otamere Okundia
}

\author{
Article by Orji Ikechukwu Anthony \\ Disease Control Unit, Health Department, AMAC, Abuja, Nigeria \\ E-mail: drtony2013@gmail.com
}

\begin{abstract}
This is a review of the article titled "The burden of hypertension and diabetes mellitus in rural communities in southern Nigeria" written by the duo of Alphonsus Rukevwe Isara \& Patrick Otamere Okundia as published in the journal Pan African Medical Journal of February, 2015, volume 20: page 103, with DOI number; doi:10.11604/pamj.2015.20.103.5619, and accessed from, http://www.panafrican-medjournal.com/content/article/20/103/full/. The review covered the evaluation of related literature, the structure of the article, authority, currency, accuracy, relevance, objectivity and stability. Furthermore, appraisal of the tables, recent advances, credibility and accessibility of the article were carried out. The objective of the original article was to determine the prevalence of hypertension and diabetes mellitus among adult residents of rural communities in southern Nigeria. Chronic diseases such as hypertension, diabetes \& obesity evidently had been on the increase and now are of public health importance in rural communities of developing countries, where it has been shown to complicate the outcome of cardiovascular diseases. The authors employed a cross- sectional survey method to screen adult residents of the selected rural communities in Southern Nigeria. Blood pressure, random blood sugar, weight, and height were measured and Body Mass Index was calculated from height /weight, as well, the respondents were interviewed with the aid of a structured interviewer-administered questionnaire. The result showed one-third of the participants had hypertension, one-third were obese/ overweight, while about 4\% had diabetes amongst others. Overall, this is an objectively written article, credible in all ramifications and has contributed to the body of knowledge on the topic especially in this part of the world. The challenge of hypertension, diabetes, and obesity is enormous and requires urgent intervention to forestall the rising trend of these disease conditions and its attendant complications in developing countries.
\end{abstract}

Keywords: Hypertension, Diabetes, Obesity, Overweight, Prevalence, Rural Communities.

\section{Introduction}

This article review critically reviews the article "The burden of hypertension and diabetes mellitus in rural communities in southern Nigeria" authored by the pair of Alphonsus Rukevwe Isara \& Patrick Otamere Okundia in the journal Pan African Medical Journal. The subject of this study is one that has continually raised valid public health concerns considering the persistently rising prevalence of chronic illnesses in rural communities of Nigeria. Co-morbid factors like obesity are also on the increase in developing countries, complicating the outcome of cardiovascular diseases, thus, the proper timing of this study cannot be overemphasized. The review at the first instance presented the evaluation of relevant literature as it concerns the topic and as well outlined the summary of the article. Following it is a brief analysis of the effectiveness of the article's structure, and an exploration of the arrangement of the information in the article whether the person who reads it can efficiently access the information. Furthermore, the review took on, the critique of the article, appraising its authority, currency, accuracy, relevance, objectivity, and stability. The tables were also analyzed, in addition to the evaluation of recent advances related to the topic of discussion before lastly judging the credibility as well as the accessibility of the article. 
Texila International Journal of Public Health

Volume 5, Issue 2, Jun 2017

\section{Review of literature}

Hypertension remains the commonest cardiovascular disease with its attendant public health challenge, responsible for up to half of all cardiovascular death. (Park.2003). Hypertension is a systolic blood pressure of greater than or equal to $140 \mathrm{mmHg}$ and/or diastolic BP of $90 \mathrm{mmHg}$ or greater (WHO. 2003). The Hypertension prevalence of $37.4 \%$ found in this community study is much higher than $13 \%$ recorded by Asekun-Olarinmoye et.al, 2013 in Osun State and 25.1\% by Ulasi et.al, 2010 in Enugu State. There is indeed a high prevalence of hypertension in sub-Saharan Africa as recorded by Opie et.al, 2005; as well the risk factors are more common in developing countries (Ibrahim, 2012).

According to WHO (2015), the mortality burden of diabetes has reached up to 1.5 million deaths by 2012, which fact was supported by IDF, 2006 reporting even a higher rate. Shaw et.al, (2009), stated that the global prevalence of diabetes among adults between the ages of $20 \& 79$ years, will be 6.4\%, affecting 285 million adults, in 2010, however, by 2014, the estimate has risen to $9 \%$ according to World Health Organization, 2015 report. This development is worse for developing countries which harbor more than $4 / 5$ of these cases. Furthermore, Abubakar et.al, 2008 also reported a rising trend of diabetes prevalence in Nigeria and Ghana.

Overweight and obesity is defined as the excessive accumulation of fat in the body. Obesity has severe negative health impact leading to bad outcome and death due to cardiovascular diseases (Akpa et.al 2008). This can be measured by using the body mass index (BMI). Obesity is fast becoming a public health challenge in developing countries as a prevalence of $32.4 \%$ was recorded in this study. Similarly, $31.1 \%$ prevalence was found in the study by Asekun-Olarinmoye et.al, 2013 in Osun State while 38.8\% prevalence was found by Ulasi et.al, 2010 in Enugu State. Moreover, Jafar (2006) recorded a prevalence of 25\% in an Indo-Asian population of Pakistan. According to the work of Iloh et.al, 2011, obesity is an emerging serious health concern in rural communities in Nigeria.

\section{Article summary}

The objective of the article was to determine the prevalence of hypertension and diabetes mellitus among adult residents of rural communities in southern Nigeria. The study is a community-based cross sectional survey which conducted the screening of adult residents of the selected communities for hypertension and diabetes mellitus using a blood pressure monitoring device and a glucometer device respectively. The respondents Body Mass Index (BMI) were also calculated using their weight and height measurement; as well they were interviewed with the aid of a structured pre-tested questionnaire. The research work showed an alarmingly high prevalence of hypertension and obesity among the respondents where more than one-third of the participants had hypertension, while about one-third were obese/ overweight in these rural communities in Southern Nigeria. The study further revealed that obesity/overweight was a significant predictor of hypertension and diabetes, while age above 40 years and being a male was a predictor of hypertension. It showed that obese people are twice more likely and four times more likely to have hypertension and diabetes respectively while for diabetes, the obese are five times more likely to develop it. This calls for increased effort towards health promotion and education program directed at prevention and control of hypertension, diabetes, and obesity in rural communities in Nigeria.

\section{Article structure}

The article title, authors and their correspondence were presented followed by an abstract which briefly introduced the problem statement and the objective of the study, the methods, result and brief conclusion. Thus in a quick glance, the abstract gives a succinct summary of 
the research study. Following the abstract is the body of the article which contained the various requisite sections as is normally contained in the report of a study of this kind. This makes it easy for a reader to quickly access the information contained in the report. These sections include; introduction, methods, results, discussions, conclusion. Others are the conflict of interest declaration, authors' contributions, acknowledgment, the list of tables and references. The introduction mentioned the background of the study, the statement of the problem and clearly stating the burden of hypertension and diabetes backed up by facts from the literature reviewed, then, stating the hypothesis and the objective of the study. Thereafter, the methods outlined the study design, setting, and population as well as the instrument of data collection, the measurements, and techniques of data analysis that was used. The sample size was documented and is adequate for the study, the described process fits random sampling technique, however, it was not categorically stated and the formula for sample size calculation was also not stated. The limitation of the method used was acknowledged, relating to the use of random instead of Fasting blood glucose measurement. Ethical consideration was also properly documented. The result section showed the salient findings as aligned to the objective of the study, the tables were used to facilitate a clear understanding of the results. Moving further, discussion section addressed the area of focus in the research and enriched with comparisons from citations of previous studies which were clearly referenced, and the limitations to guide future research on the topic. Finally, the conclusion which was unusually very short, lacking depth, though, it was able to highlight the success of the research in achieving its objective. By and large, the body of the research was logically developed.

\section{Critique}

\section{Authority}

Pan African Medical Journal (PAMJ) is one of the leading peer review journals of high repute in Africa. PAMJ in the process of publishing articles collaborates with African Field Epidemiologist Network (AFENET), a reputable association of epidemiologist in Africa. The article was searched using Google Scholar and Pub Med/Medline; both are credible research search engines. The author is an authority in the field of Public Health/Epidemiology with a profile that speaks volumes: a Consultant/Specialist Public Health Physician, Epidemiologist and an academician with the UBTH, Benin City, a foremost premier University in Nigeria. An author of several other articles published in peer review journals, a researcher with many years of research experience.

\section{Accuracy}

The research study, from which the information in the article was originated, is a current work of about two years old. The reference lists from where citations in the body of the text were made are current research works, thus, giving the necessary support to the accuracy of the information in the text. Furthermore, the peer review journal adopts a stringent review and editorial standard in the process of accepting articles for publication. Moreover, the other expert sources linked to the article upholds the accuracy of the work. Overall, the accuracy of the work is substantially optimal.

\section{Currency}

The Pan African Medical Journal received this article in October 2014, accepted the article in January 2015 and published it in the journal in April 2015.This is a most recent and current research work. Moreover, the references cited in the body of the text of the article were up to date works with range for most of the works between 2006 and 2014, and only four of the works were 1997 and 2003. Against the backdrop of the aforementioned, the article is a current research work that dealt on a very topical and contemporary health issue and can be relied upon. 
Texila International Journal of Public Health

Volume 5, Issue 2, Jun 2017

\section{Relevance}

This is a journal for health professionals, students, academicians, policy makers and organizations with interest in issues regarding the health of Africans. It is highly credible in the context of the above-listed groups. The article was written to enlighten academicians, researchers, policy makers and organizations interested in the control of non-communicable diseases in Nigeria in particular and Africa at large. It would be very relevant to these groups, the researchers as a baseline for further research, the academicians for teaching, the policy makers for an informed decision as regards planning of health intervention projects to control non-communicable diseases and organizations for planning and implementation of such programs.

\section{Objectivity}

The objectivity of the information in the article is glaring. The research was well designed and conducted following all the rigors involved in a population-based research. The objective was clearly stated at the beginning and was seen to be achieved by the findings of the study. The references were current, appropriately cited, acknowledged and used to support the research decisions at the appropriate sections. The sample population was clearly defined as adult residents of the selected communities 18 years and above with the possibilities of generalizing the findings to other rural communities in the region as well the repeatability of the research studies.

\section{Stability}

This a stable resource article on the background of it source being a reputable peer-review journal for academic, health professional, policy maker, and stakeholders reference. It can be used in academic institutions by academicians for teaching and research, for health sector research, for public health intervention program development and the likes.

\section{Analysis of graph/Chart/Table}

Table 1: Social-Demographic Characteristics of Respondents

It is well outlined with the independent variables clearly delineated. The information is relevant, clearly stated, well arranged, and making it easily accessible.

Table 2: Prevalence of Hypertension and Diabetes Mellitus in rural communities

The table shows the results of the primary outcome variables, well outlined, properly labeled and clearly presented.

Table 3: The demographic characteristics and hypertensive status of respondents

The table depicts the association between the dependent variable and the independent variable, clearly stated, easily understood and relevant to the objective of the study.

Table 4: Respondents Demographic characteristics and diabetes mellitus status

This also depicts the association between the dependent and the independent variable, clearly stated, easily understood and relevant to the objective of the study.

Table 5: Multinomial logistic regression for the predictors of hypertension and diabetes mellitus in rural communities

The table is relevant, clearly stated and properly labeled.

\section{Recent advances related to the topic}

According to Thompson Noelle (2015), the measurement of Body Mass Index (BMI) has witnessed some advancement away from the traditional use of weight and height measurement. The traditional method formulae are 1. Weight in kilogram multiplied by height in meters squared [weight $(\mathrm{kg}) \mathrm{x}$ height $(\mathrm{m} 2)$ ] or 2 . Weight in pounds multiplied by height in inches squared multiplied by 703 , [weight (lb) $x$ height (in2) $x$ 703].

The use of a handheld device developed for BMI is fast and easy and is becoming more popular than the traditional method. The mechanism of operation of the device is through the sending of safe electrical current through the body with subsequent measurement of the 
resistance which the current encounters. The current travels fast through water but not through fat, thus, the higher the resistance, the higher the fat, thereby taking into account other factors that can affect the fat composition of the body like, muscle, sex of individual and age. The traditional method does not take into account these factors. This method is easy and fast and can become very useful in large-scale community-based studies by reducing the burden of BMI measurement and saving time and fund for the research. Further advancement in BMI measurement is the underwater method which is more accurate than the handheld device but its cumbersome and not a fast method, therefore, not suitable for a large-scale survey.

Moreover, research in this area of non-communicable diseases can include blood lipids measurement in order to cover metabolic syndrome as a whole entity. Bringing in triglyceride and cholesterol measurement has become very important as this is another co-morbid primary factor of the variables under study. In this case, obesity measurement can be done using the abdominal gait/ waist circumference measurement which to a large extent is superior to the use of BMI, especially as the age advances.

\section{Conclusion}

This is an article review which has evaluated, appraised and critiqued the structure, content, strengths and weaknesses of the study 'The burden of hypertension and diabetes mellitus in rural communities in southern Nigeria'. Overall, this is an objectively written article, credible in all ramifications and has contributed to the body of knowledge on the topic especially in this part of the world. Improvement on the article could be in the methodology, especially in the area of stating formula for sample size calculation, sampling technique, in addition to an in-depth conclusion. The challenge of hypertension, diabetes, and obesity is enormous and requires urgent intervention to forestall the rising trend of these disease conditions and its attendant complications in our society. There is an urgent need to give attention to non-communicable diseases, to save thousands of lives being cut off by the complications of these 'silent killers'. Health education and awareness for lifestyle changes, screening and early treatment of these conditions should be institutionalized in our health systems especially the primary health care system. The result of this research will be very useful to health authorities at local, state and federal government level for policy reforms as regards non-communicable disease control programs. The article is very accessible, current and relevant for academics, further research and policy decision making as regards public health intervention programs. It has also shown areas of further research.

\section{References}

[1]. Abubakari A.R. \& Bhopal R.S. (2008). A systematic review on the prevalence of diabetes overweight/obesity and physical inactivity in Ghanaians and Nigerians. Science direct journal of Public health. 122 (2), 173-183. Doi 10.1016/j.puhe.2007.06.012.

[2]. Akpa, M.R. \& Mato, C.N. (2008). Obesity in Nigeria: Current trends and management. Nigerian Medical Practitioner. 54 (1), 11-15. Retrieved from

http://www.ajol.info/index.php/nmp/article/view/28941

[3]. Asekun-Olarinmoye E.O., Akinwusi, P.O., Adebimpe, W.O., Isawumi, M.A., Hassan, M.B., Olowe, O.A., Adewole, T.A. (2013). Prevalence of hypertension in the rural adult population of Osun State, southwestern Nigeria. International journal of general medicine. 6, 317-322. DOI: http://dx.doi.org/10.2147/IJGM.S42905

[4]. Ibrahim M.M. \& Damasceno A. (2012). Hypertension in developing Countries. The Lancet. 380 (9841), 611-619.

[5]. IDF (2006): The IDF consensus worldwide definition of the metabolic syndrome. Retrieved from Http://www.IDF.org/web data/docs/IDF_Meta_def_final.pdf

[6]. Iloh G.U.P., Amadi A.N., Nwankwo B.O. \& Ugwu V.C. (2011). Obesity in adult Nigerians: A study of its pattern and common primary co-morbidities in a rural Mission General Hospital in Imo state, south-eastern Nigeria. Nigerian journal of clinical practice. 14 (2), 212-216. 
Texila International Journal of Public Health

Volume 5, Issue 2, Jun 2017

[7]. Jafar J.H., Chaturvedi N. \& Pappas G. (2006). Prevalence of overweight and obesity and their association with hypertension and diabetes mellitus in an Indo-Asian population. Canadian Medical Association Journal. 175(9), 1071-1077. doi: 10.1503/cmaj.060464.

[8]. Lucas A.O \& Gilles H.M. (2003). Short Textbook of Public Health Medicine for the Tropics, 4th Ed., London, Hodder Arnold. 236-237.

[9]. Opie L.H. \& Seedat. Y.K. (2005). Hypertension in Sub-Saharan African Populations. American Heart Association Journal. 112, 3562-3568. Doi: 10.1161/CIRCULATIONAHA218. Retrieved from http://www.njcponline.com/article.asp

[10]. Park, K. (2013). Park's textbook of Preventive and Social Medicine, 21st Ed., Jabalpur, India. Bhanot. 344-346.

[11]. Shaw J.E., Sicree R.A. \& Zimmet P.Z. (2009). Global estimates of the prevalence of diabetes for 2010 and 2030. Baker IDI Heart and Diabetes Institute, Australia. 87(1), 4-14. Doi: http://dx.doi.org/10.1016/j.diabres.2009.10.007

[12]. Thompson N. (2015).How does handheld BMI machine work? Retrieved from http://www.livestrong.com/article/558509-how-does-a-handheld-bmi-machine-work/

[13]. Ulasi, I.I, Ijoma C.K., \& Onodugo D.O. (2010). A community-based study of hypertension and cardio-metabolic syndrome in semi-urban and rural communities in Nigeria. BMC Health Services Research. 10(71) DOI: 10.1186/1472-6963-10-71.

[14]. WHO. (2003). World Health Organization: International Society of Hypertension Writing Group. World Health Organization/International Society of Hypertension (ISH) statement on management of hypertension. J Hypertens. 21, 1983-1999.

[15]. WHO, (2015). Diabetes Fact sheet. Retrieved from

http://www.who.int/mediacentre/factsheets/fs312/en/

[16]. Website: Alphonsus Rukevwe Isara \& Patrick Otamere Okundia, 2015, 'The burden of hypertension and diabetes mellitus in rural communities in southern Nigeria', Pan African Medical Journal, February 2015, 20:103 doi:10.11604/pamj.2015.20.103.5619, viewed 01 June 2015 